\title{
Research Article \\ Reducing Railway Noise with Porous Sound-Absorbing Concrete Slabs
}

\author{
Caiyou Zhao, ${ }^{1,2}$ Ping Wang, ${ }^{1,2}$ Li Wang, ${ }^{1,2}$ and Dan Liu ${ }^{1,2}$ \\ ${ }^{1}$ Key Laboratory of High-Speed Railway Engineering, Southwest Jiaotong University, Ministry of Education, Chengdu 610031, China \\ ${ }^{2}$ School of Civil Engineering, Southwest Jiaotong University, Chengdu 610031, China \\ Correspondence should be addressed to Caiyou Zhao; zcy848279@163.com
}

Received 9 July 2014; Accepted 13 November 2014; Published 30 November 2014

Academic Editor: Jiangbo Sha

Copyright (c) 2014 Caiyou Zhao et al. This is an open access article distributed under the Creative Commons Attribution License, which permits unrestricted use, distribution, and reproduction in any medium, provided the original work is properly cited.

\begin{abstract}
The effect of porous sound-absorbing concrete slabs on railway noise reduction is examined in this paper. First, the acoustical absorption coefficients of porous concrete materials with various aggregate types, gradations, fibre contents, and compaction indexes are measured in the laboratory. The laboratory results show that porous concrete that uses a composite of expanded perlite and slag as aggregate can not only obtain good acoustical absorption properties but also satisfy mechanical requirements. Also, the gradation of the combined aggregate has a significant effect on the acoustic absorption performance of the porous concrete, with an optimal aggregate gradation of 1 3 mm. Furthermore, the fibre content and compaction index affect both the strength and the acoustic absorption property of the porous concrete, with the optimum value of $0.3 \%$ and 1.6 , respectively. Then, the findings from the laboratory studies are used to make porous sound-absorbing concrete slabs, which are applied in a test section. The measurements indicate that porous sound-absorbing concrete slabs can significantly reduce railway noise at different train speeds and that the amount of the noise reduction changes roughly linearly with speed when the train is traveling at less than $200 \mathrm{~km} / \mathrm{h}$. The maximum noise reduction is $4.05 \mathrm{~dB}$ at a speed of $200 \mathrm{~km} / \mathrm{h}$.
\end{abstract}

\section{Introduction}

In recent years, due to accelerated industrialisation, urbanisation, and economic development in China, rail transit, especially high-speed railways, has experienced a rebirth in both development scale and level in China. Compared with ballasted track, ballastless track is advantageous due to its excellent stability, low maintenance, and ability to preserve geometry; therefore, it has been widely used in railway construction in China [1]. However, ballastless track has higher sound emissions due to reduced connecting impedance for the rail, reduced vibration decay rates along the rail, and reduced absorption [2]. Field test results proved that the noise of the ballastless track is approximately $5 \mathrm{~dB}$ higher than that of ballasted track for the receiver at the boundary of the railway [3].

As a result, railway noise is a growing public concern in China, prompting the railway management department to use various techniques and methods to mitigate noise. A noise barrier is one of the most widely used methods in the railway noise treatment field at this time. However, it is very costly to build and maintain a noise barrier, and, in many cases, it generates a strong, uncomfortable visual impact and secondary noise. Furthermore, the central issue of noise barriers is that they do nothing to prevent the noise but merely create local regions of noise reduction [4]. The railway management department is therefore paying increasing attention to alternative solutions. According to relevant research, noise from the lower parts of the car, which consists of rolling noise, equipment noise, and noise from the motor fan, is the main contributor to the overall noise level when the train is traveling at a speed of less than $300 \mathrm{~km} / \mathrm{h}$. Therefore, the primary task of reducing railway wayside noise is to abate noise from the lower parts of the car [5]. However, in terms of noise reduction efficiency, noise abatement measures should be arranged close to the noise sources as much as possible. Therefore, with the aim of absorbing noise from the lower parts of the car body through multiple sound reflections between the car body and the track slab, laying slabs made of sound absorption materials 
on the surface of ballastless track is a very promising noise mitigation method [6].

Porous concrete is a rigid-framed sound absorption material containing open voids and interconnected pores and has been intentionally fabricated for sound absorption [7]. When an acoustic wave enters the pores of porous concrete, the acoustic energy that propagates in the interconnected voids is dissipated via conversion to heat by virtue of wave refraction and interference occurring inside of the void texture [8]. Although other sound absorption materials also absorb sound waves, porous concrete is more widely applied in civil engineering fields due to its excellent mechanical properties and durability [9].

Many studies have been conducted in the past to investigate noise abatement characteristics of porous concrete and its applications in civil engineering fields [10-13]. In general, these studies focus on the application of porous concrete in highway sound barriers or pavements to absorb traffic noise and reduce sound wave reflection. However, little guidance is provided for porous concrete and its applications in railways.

The research presented herein focuses on an exploratory evaluation of the acoustic absorption of porous concrete using laboratory tests and an evaluation of the noise reduction of sound-absorbing porous concrete slabs using field tests. First, the mechanical and structural requirements of the sound-absorbing slabs are studied in accordance with railway standards. Next, laboratory porous concrete specimens with various aggregates, fibre contents, and compaction indexes are prepared and tested to characterise their acoustic absorption and mechanical properties. Finally, the optimal porous concrete combination is used to manufacture porous sound-absorbing concrete slabs, which are applied in a test section. The railway wayside noise is measured in the test section according to Chinese National Standards (GB 1252590 ) and is compared with the noise data obtained from the conventional adjacent section.

\section{Mechanical and Structural Requirements}

Maintaining operational safety is a prerequisite for the application of porous sound-absorbing concrete slabs on railways. Therefore, the mechanical and structural requirements should be adhered to in slab design.

2.1. Thickness Requirement. Previous studies have demonstrated that the thickness of the sound-absorbing slab has great influence on its sound absorption performance, especially for low frequencies. A thicker sound-absorbing slab has better sound absorption effects at low frequencies. Therefore, slab thickness should be increased accordingly, within an acceptable range. However, given the distance of approximately $257 \mathrm{~mm}$ between the rail head and track slab and that the top surface of the slab cannot be higher than the rail head, the thickness of the slab should be less than $257 \mathrm{~mm}$. Additionally, the maximum vertical compression deformation of fastening systems is approximately $20 \sim 30 \mathrm{~mm}$, the largest vertical wear of the rail is $10 \mathrm{~mm}$, and the minimum elevation difference between the slab and the rail head is $10 \mathrm{~mm}$; therefore, the maximum thickness of the slab can be
$207 \mathrm{~mm}$. For safety reasons, the thickness of the slab should be $200 \mathrm{~mm}$.

2.2. Compressive Strength Requirement. On a railway, the space between the rails should be accessible not only for railway workers performing maintenance but also for emergency work; therefore, the porous concrete sound-absorbing panel must demonstrate good performance as well as sufficient compressive strength. According to Chinese Railway Standards (TB10002.1-2005), vertical load is set at $1.5 \mathrm{kN}$ for calculations. Furthermore, for the cement-based porous sound-absorbing material, the CMT5105 universal testing machine was used to test its compressive strength, with a $4 \mathrm{~cm}$ $\times 4 \mathrm{~cm} \times 16 \mathrm{~cm}$ rectangular column specimen according to Chinese National Standards (GB/T 17671-1999). Using a safety factor of 1.25 , the compressive strength should be more than $1.175 \mathrm{Mpa}$.

2.3. Wind Resistance Requirement. When a train travels at high speed, turbulence and strong pressure are produced around the train, while a great negative pressure adhering force is produced in the lower part of the vehicle body. Therefore, the porous sound-absorbing concrete slabs laid on the track slab must have sufficient density. In situ tests and numerical simulations show that the maximum negative pressure of the lower parts of the vehicle body is approximately $423 \mathrm{~Pa}$ when the vehicle travels at a speed of $270 \mathrm{~km} / \mathrm{h}$. Because the maximum negative pressure is proportional to the square of the train speed, the maximum negative pressure will be $710 \mathrm{~Pa}$ when the speed is $350 \mathrm{~km} / \mathrm{h}$. Taking the higher speed, crosswinds, installation errors, and other factors into consideration, the maximum negative pressure should be multiplied by a safety factor of 2 . Therefore, the density of the sound-absorbing slabs should be greater than $710 \mathrm{~kg} / \mathrm{m}^{3}$.

These requirements are the essential prerequisites for the successful development of a porous sound-absorbing concrete slab. The following design of a porous soundabsorbing concrete slab should satisfy these requirements.

\section{Test Methods and Setup for Laboratory Testing}

\subsection{Materials}

3.1.1. Cement. To ensure that the porous sound-absorbing concrete slab has enough strength, P.O52.5 cement is used for this study. (P.O means Ordinary Portland Cement. Strength grade 52.5 means that the standard compressive strength value of cement at $28 \mathrm{~d}$ is not lower than $52.5 \mathrm{MPa}$, by the test procedures in standard ISO 679: 1989; 52.5 Mpa is taken as the nominal strength of cement to be used in concrete.) Its main parameters are shown in Table 1.

3.1.2. Aggregate. There are three types of coarse aggregates: expanded perlite, clay ceramsite, and slag, and each type of aggregate is used in three different sizes (number 1 (0-2 mm), number $2(1-3 \mathrm{~mm})$, and number $3(1-5 \mathrm{~mm}))$ to prepare all porous concretes. Photos of the three types of coarse aggregates are shown in Figure 1. The expanded perlite is 
TABLE 1: Parameters of P.O52.5 cement.

\begin{tabular}{|c|c|c|c|c|c|c|c|}
\hline \multirow[t]{2}{*}{$80 \mu \mathrm{m}$ sieve residue (\%) } & \multicolumn{2}{|c|}{ Setting time (min) } & \multicolumn{2}{|c|}{$\begin{array}{l}\text { Flexural strength } \\
\text { (Mpa)_ISO 679:1989 }\end{array}$} & \multicolumn{2}{|c|}{$\begin{array}{l}\text { Compression strength } \\
\text { (Mpa)-ISO 679:1989 }\end{array}$} & \multirow[t]{2}{*}{ Stability } \\
\hline & Initial setting time & Final setting time & $3 \mathrm{~d}$ & $28 \mathrm{~d}$ & $3 d$ & $28 \mathrm{~d}$ & \\
\hline 1.5 & 139 & 205 & 4.5 & 7.8 & 25.1 & 55.5 & Qualified \\
\hline
\end{tabular}

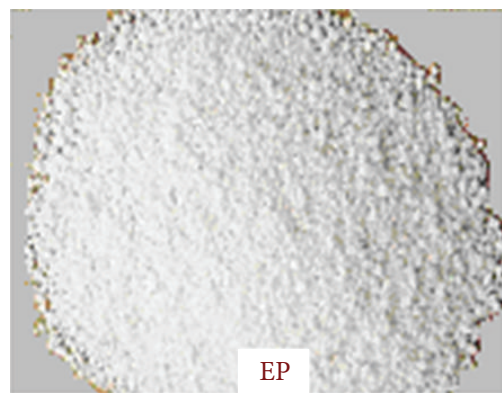

(a) Expanded perlite

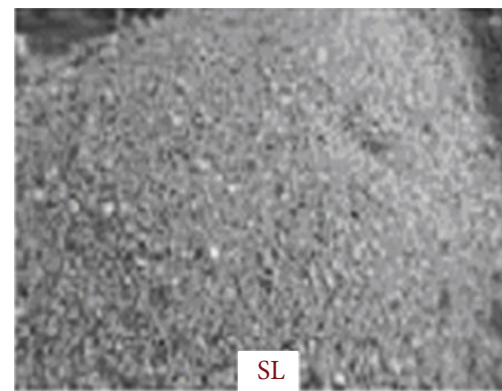

(b) Slag

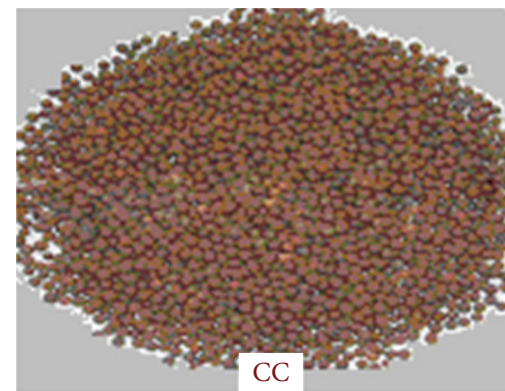

(c) Clay ceramsite

FIgURE 1: Photos of aggregates.

a white, porous, and granular material. It is preferred for its light weight, heat insulation, sound absorption, nontoxicity, lack of odour, and fireproofing. The main physical properties of expanded perlite are as follows: bulk density, $80 \mathrm{~kg} / \mathrm{m}^{3}$; moisture content by mass, $2.5 \%$; water absorption by volume, up to $27 \%$; thermal conductivity, $0.40 \mathrm{~W} /(\mathrm{m} \cdot \mathrm{K})$; and moisture absorption, $0.015 \%$. The ceramsite used in this study is light weight and high strength. The technical performance is as follows: bulk density, $450 \mathrm{~kg} / \mathrm{m}^{3}$; cylinder compressive strength, $1.65 \mathrm{MPa}$; and water absorbing capacity, no more than $17.6 \%$. The adopted slag is loose in texture, porous, and in the shape of a grain, with the main performance as follows: bulk density, $720 \mathrm{~kg} / \mathrm{m}^{3}$, and moisture content by mass, no more than $1.25 \%$.

3.1.3. Fibre. Polypropylene fibres range in length from $8 \mathrm{~cm}$ to $18 \mathrm{~cm}$. Polypropylene fibre has many advantages, including chemical corrosion resistance, high wet strength, light weight, small creep and shrinkage, low price, low rates of concrete cracking, a toughening effect, and excellent technical and economic performance. Table 2 shows its main technical indicators.

3.1.4. Admixture. A commercially available high water reducing agent (density: $1.06 \mathrm{~g} / \mathrm{cm}^{3}$ ), a foaming agent (density: $1.02 \mathrm{~g} / \mathrm{cm}^{3}$ ), and a foam-stabilising agent (density: $0.98 \mathrm{~g} / \mathrm{cm}^{3}$ ) are applied for the porous concretes. A water reducing agent is added to improve the strength and workability of porous concrete. The foaming agent is applied to make cement form open voids and interconnected pores during the hydration process by generating foam via chemical reactions, whereas the foam-stabilising agent helps by increasing the internal friction of cement paste in the flow and then increasing the foam viscosity. As a result, the rupture time of the foam is delayed, and the stability is increased. The amounts of these admixtures are calculated according to cement weight.
3.2. Procedure. The dry mixture is obtained through uniformly mixing cement, aggregates, and other additives in a certain mass ratio. The slurry is adjusted after mixing the water and foaming agent with the dry mixture. After vibrating, moulding, and demoulding, a material with uniform pores is obtained. The samples are first covered with a preservative film for $24 \mathrm{~h}$ after demoulding, followed by $28 \mathrm{~d}$ to cure under standard conditions. Finally, the sound absorption coefficient and the strength of the samples are examined. The technological process of preparing porous concrete specimens is illustrated in Figure 2.

3.3. Characterisation. In accordance with ASTME 1050-98, the acoustic absorption of porous concrete is evaluated by using a Sheng Wang impedance tube as shown in Figure 3(a). A specimen with a length of $200 \mathrm{~mm}$ is tested. The sample is placed inside of a thin cylindrical Teflon sleeve to reduce the risk of scratching the inside of the impedance tube. This assembly, consisting of the cylinder and the Teflon sleeve, is placed against a rigid backing at one end of the impedance tube. The other end of the tube is equipped with a sound source. Microphones placed along the length of the tube are used to detect the sound wave pressures, which are transmitted to the sample, with a portion reflected by the rigid termination, as shown in Figure 3(b). The pressure reflection coefficient $(R)$ is defined as the ratio of the pressure of the reflected wave to that of the incoming wave, at a particular frequency. The pressure reflection coefficient can be expressed as

$$
R=\frac{e^{j k x_{1}}-e^{j k x_{2}} P}{e^{-j k x_{2}} P-e^{-j k x_{1}}},
$$

where $x_{1}$ and $x_{2}$ are the distances from the specimen surface to the closest and farthest active microphone, respectively, as shown in Figure 3(b); $j$ is an imaginary number; $k$ is the wave number (ratio of angular frequency to the wave speed 
TABLE 2: Technical indicators of fibre.

\begin{tabular}{lcccccc}
\hline $\begin{array}{l}\text { Density } \\
\left(\mathrm{g} / \mathrm{cm}^{3}\right)\end{array}$ & $\begin{array}{c}\text { Compressive } \\
\text { strength }(\mathrm{MPa})\end{array}$ & $\begin{array}{c}\text { Elastic modulus } \\
(\mathrm{MPa})\end{array}$ & Colour & $\begin{array}{c}\text { Break elongation } \\
\text { ratio }\end{array}$ & $\begin{array}{c}\text { Melting point } \\
\left({ }^{\circ} \mathrm{C}\right)\end{array}$ & $\begin{array}{c}\text { Flash point } \\
\left({ }^{\circ} \mathrm{C}\right)\end{array}$ \\
\hline $0.90-0.95$ & $\geq 340$ & $\geq 3500$ & White & $10-35 \%$ & 165 & 560 \\
\hline
\end{tabular}

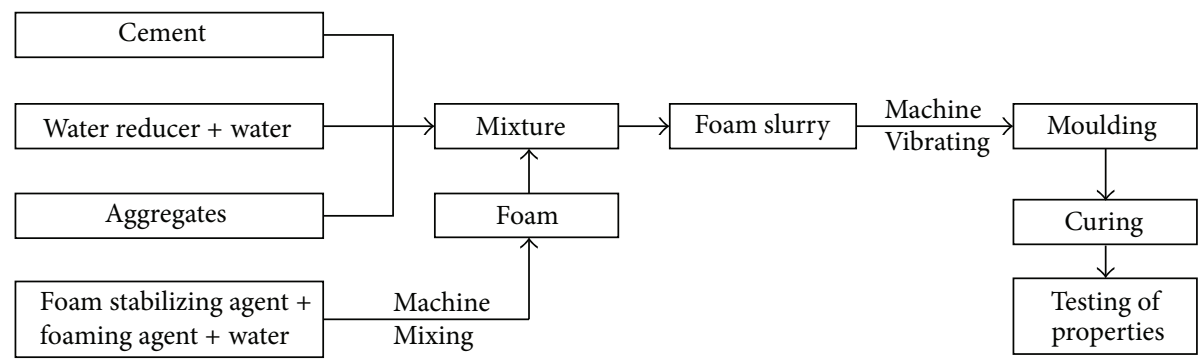

FIGURE 2: Technological process of preparation.

in the medium); and $P$ is the ratio of acoustic pressures at the two active microphone locations. Once the pressure reflection coefficients $(R)$ are determined at each frequency, the absorption coefficient for each frequency can be calculated as shown in

$$
\alpha=1-|R|^{2} .
$$

The frequency range of interest is limited from $125 \mathrm{~Hz}$ to $4000 \mathrm{~Hz}$ in this study. A threshold of $125 \mathrm{~Hz}$ is established because the acoustic pressures are difficult to stabilise at very low frequencies. The reasons for limiting the high frequency range at $4000 \mathrm{~Hz}$ are as follows. (1) The diameter of the impedance tube must be small to sustain a standing wave in the tube for higher frequencies. Due to the aggregate sizes in the material, it is difficult to prepare samples of such small sizes. (2) The range of frequencies in which railway noise is the most objectionable to the human ear is $125 \sim 4000 \mathrm{~Hz}$.

Another index noise reduction coefficient (NRC) is introduced when evaluating the sound absorption ability of porous concrete in this study. This value is an average value of sound absorption coefficients at frequencies of 250,500, 1000, and $2000 \mathrm{~Hz}$. It can be calculated by

$$
\mathrm{NRC}=\frac{\alpha_{250}+\alpha_{500}+\alpha_{1000}+\alpha_{2000}}{4}
$$

In this study, the absorption coefficient and noise reduction coefficient of laboratory-prepared specimens are measured by using standing wave tube techniques, as defined by ISO 10534-2:1998 "Acoustics-Determination of sound absorption coefficient and impedance in impedance tubesPart 2: Transfer-function method."

\section{Laboratory Testing and Results}

Porous concrete material can reduce noise because there are a large number of voids in the material. When a sound wave enters the material, the air movement is blocked or weakened once it meets the solid walls of these voids. A portion of the sound energy is transformed into heat, which is then dissipated due to the viscosity and heat conduction effects. While a noticeable portion of the sound is absorbed by the porous concrete material, a high proportion of the sound wave is bounced back to the surface and goes into the air, generating noise. This is the process of the transformation and dissipation of sound waves.

To maximise noise reduction, laboratory tests were conducted to investigate the acoustical properties of porous concrete materials using the standing-wave tube method, including tests on various aggregate types, combinations of different aggregates, aggregate grain gradations, fibre contents, and compaction indexes. The frequency of railway noise is $125 \sim 4000 \mathrm{~Hz}$. Therefore, the input sound frequency of the standing wave tube was controlled within the range of $125 \sim 4000 \mathrm{~Hz}$, and the evaluation was conducted on the acoustic performance of porous concrete material in this frequency range.

\subsection{Relation between Aggregate and Sound Absorption}

4.1.1. Influence of Aggregate Type on Sound Absorption. To study the effect of aggregate type on sound absorption, the first group of three reference samples with aggregate types of expanded perlite, clay ceramsite, and slag were studied. Cylinders (100 $\mathrm{mm}$ diameter and $200 \mathrm{~mm}$ height) and rectangular columns $(40 \mathrm{~mm} \times 40 \mathrm{~mm} \times 160 \mathrm{~mm})$ were prepared. Three replicates were made for each aggregate type.

The average of the acoustic experiment results from the three replicates is calculated and shown in Figure 4. The acoustical absorption coefficient curves for all three types of aggregate reach a peak at 400 to $630 \mathrm{~Hz}$. It was also found that the corresponding peak absorption coefficient varies with different types of aggregate. Specifically, the specimen with the expanded perlite has the maximum absorption coefficient (0.79), and the specimen with the clay ceramsite has the lowest absorption coefficient (0.68).

Figure 5 provides information about the relationship between the aggregate type and the NRC of the porous material. Aggregate type appears to have great influence on the sound absorption property of porous concrete, and 


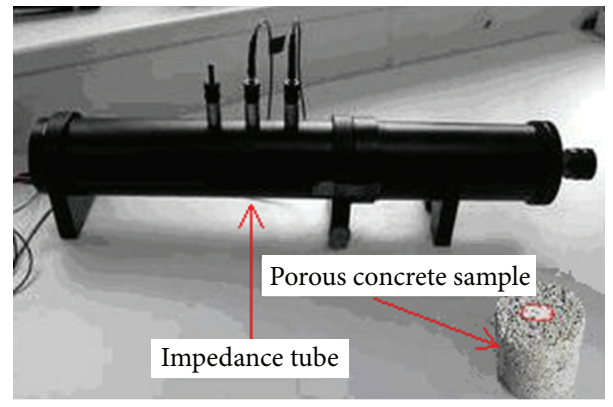

(a) Physical picture of a Sheng Wang impedance tube

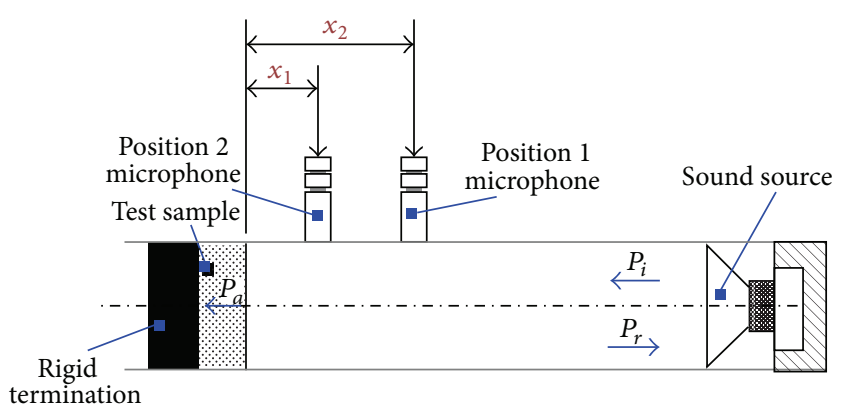

(b) Working principle diagram of an impedance tube

Figure 3: Configuration of the impedance tube.

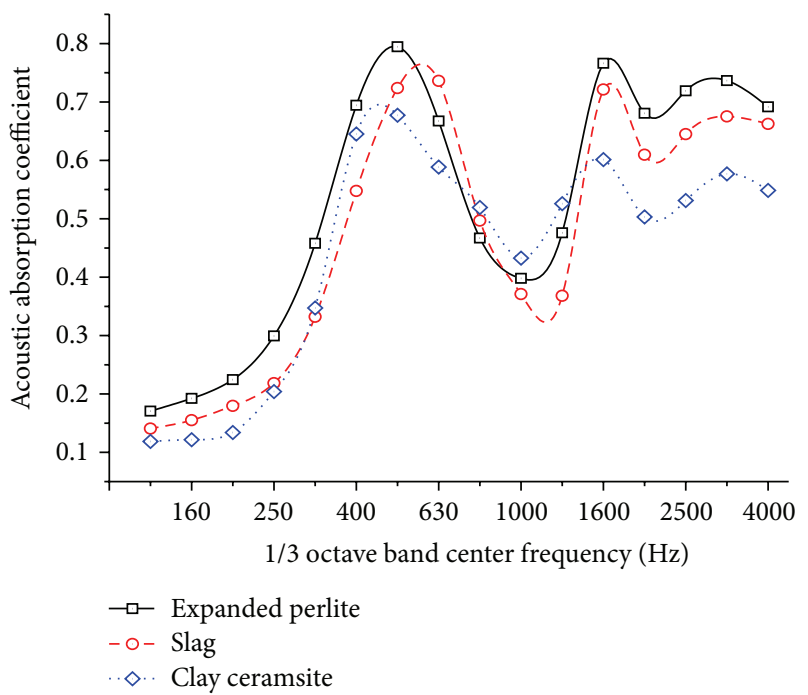

FIGURE 4: Relationship between aggregate type and sound absorption.

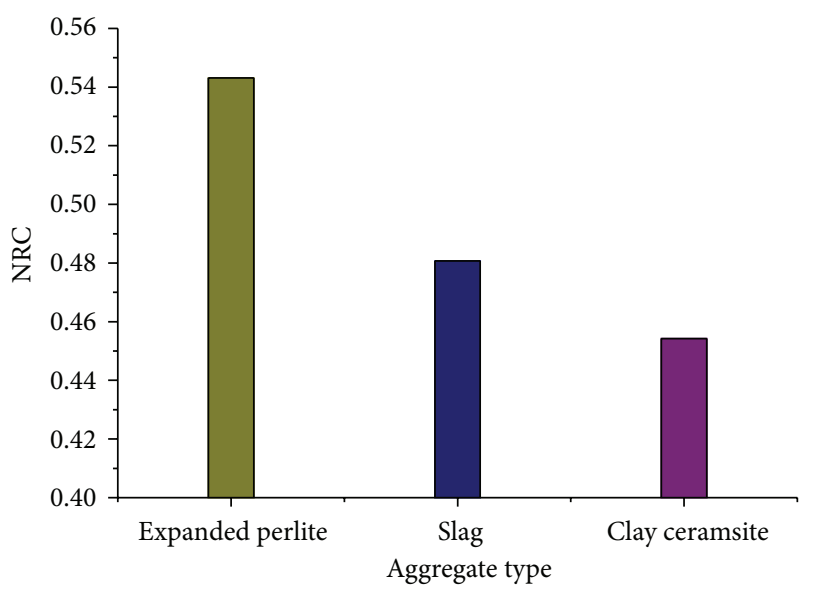

FIGURE 5: Variation of NRC with aggregate type.

the specimen with expanded perlite aggregate has the largest noise reduction coefficient (0.66). Furthermore, the noise reduction coefficients of the sample with slag and the sample with clay ceramsite are 0.58 and 0.55 , respectively.
This result occurs because the pore structure and the connectivity between internal holes and external holes are different among the three types of aggregates. Additionally, scanning electron microscope analyses indicate that the pore structure of the expanded perlite is characterised by a cellular shape, high porosity, thin hole walls, uniform pore distribution, and varied size, with the internal pores connecting to the surface. In slag, most of the holes are independent, with only some holes connected to the surface. As for clay ceramsite, although there are many independent interior holes and internally connected holes, these holes are mostly not connected to the surface. Based on the sound absorption mechanism, the structure characteristics of porous sound-absorbing material should cover the following aspects.

(a) There are many pores and apertures inside of the material, and the pores and apertures are small and uniformly distributed.

(b) Those pores and apertures are connected with each other.

(c) The pores and apertures inside of the material are connected to the outer surface.

Based on the above analysis, the porous concrete with expanded perlite aggregate has the best sound absorption property, followed by the slag; clay ceramsite exhibits the worst sound absorption property.

4.1.2. Influence of Aggregate Combination on Sound Absorption. It can be concluded from the first test group that the expanded perlite is the best choice for porous concrete in terms of sound absorption. However, the density of the product with a single aggregate type of expanded perlite is only approximately $700 \mathrm{~kg} / \mathrm{m}^{3}$, less than $710 \mathrm{~kg} / \mathrm{m}^{3}$. Thus, to increase the density of the specimen, it would be more practical to apply the composite of expanded perlite and slag as aggregate, for its higher density. In addition, the aggregates can be formed into two layers, with expanded perlite in the upper layer and slag in the lower layer.

A total of twelve combinations were studied: six with $0 \%$, $20 \%, 40 \%, 60 \%, 80 \%$, and $100 \%$ slag by volume and the rest with two layers, namely, $0+20 \mathrm{~cm}$ (the lower is slag, while the upper is expanded perlite), $4+16 \mathrm{~cm}, 8+12 \mathrm{~cm}, 12+8 \mathrm{~cm}$, 


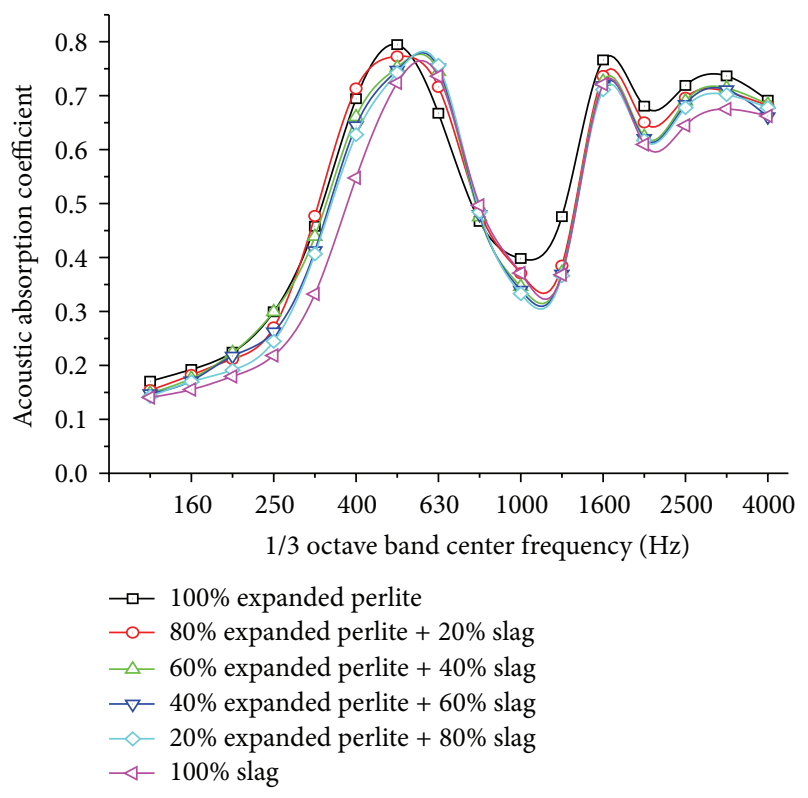

FIGURE 6: Relationship between percent slag by volume and sound absorption.

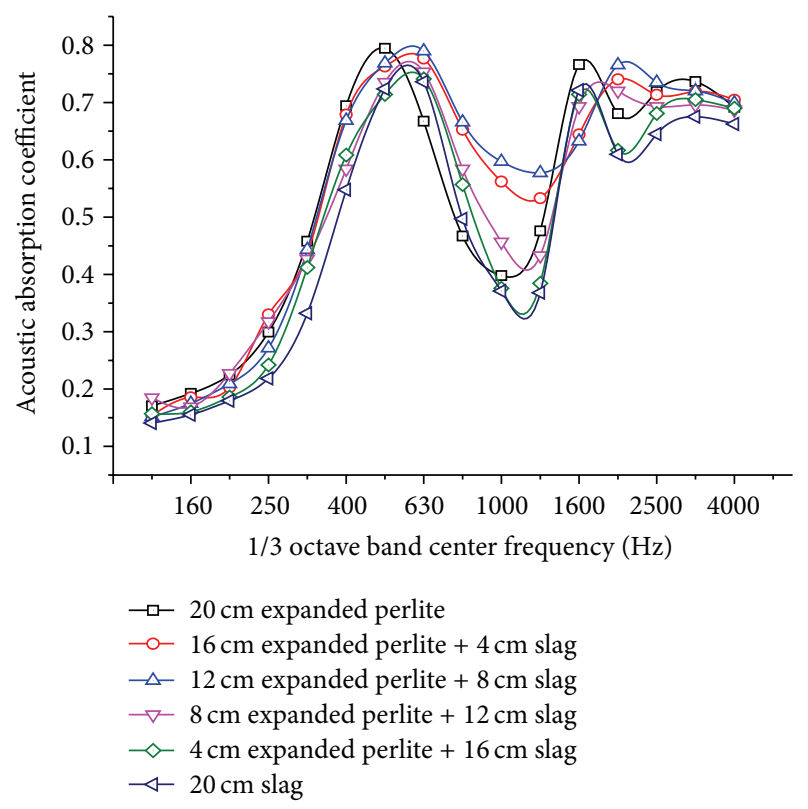

FIGURE 7: Relationship between percent slag by thickness and sound absorption.

$16+4 \mathrm{~cm}$, and $20+0 \mathrm{~cm}$. The averages of the acoustic experiment results from the three replicates are illustrated in Figures 6, 7, 8, and 9. Both the acoustic absorption coefficient and the noise reduction coefficient decrease with the increasing content of the slag in the composite application case, while the sound-absorbing performance first improves and then decreases with increasing thickness of the slag in the layering case. For the latter method, when the thickness of the slag is $8 \mathrm{~cm}$, the maximum NRC is 0.623 and the density is approximately $820 \mathrm{~kg} / \mathrm{m}^{3}$. In accordance with these

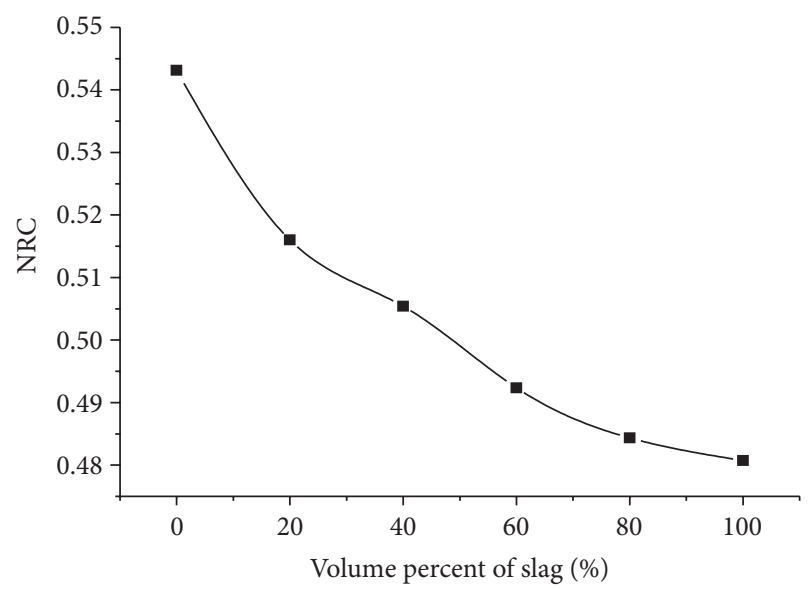

FIGURE 8: Variation of NRC with percent slag by volume by mixing method.

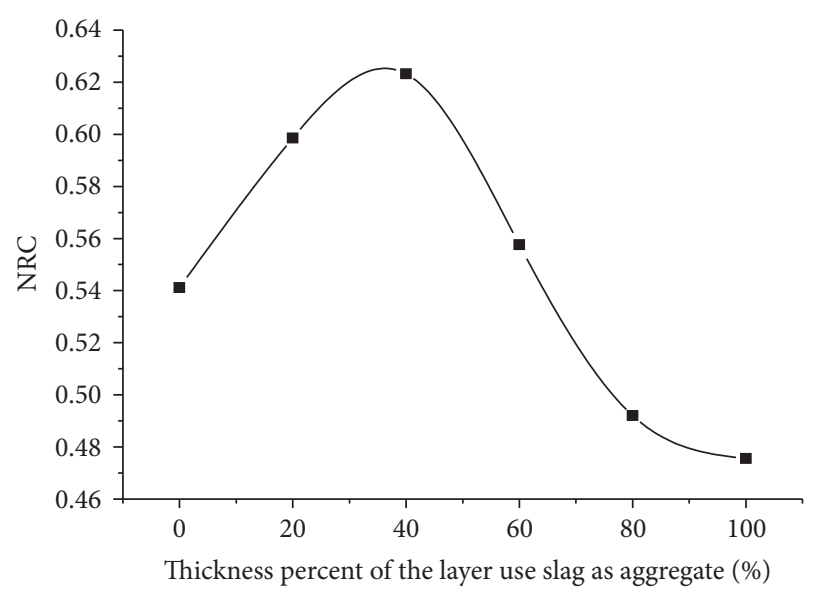

FIGURE 9: Variation of NRC with percent slag by volume with layering method.

results, the combination of $8 \mathrm{~cm}$ slag (lower layer) and $12 \mathrm{~cm}$ expanded perlite (upper layer) was adopted as the soundabsorbing material and was used in the experiment described below.

4.1.3. Influence of Aggregate Gradation on Sound Absorption. Previous studies show that aggregate gradation significantly affects the acoustic absorption property of porous concrete. The third study group was designed with different aggregate gradations of $0 \sim 2 \mathrm{~mm}, 1 \sim 3 \mathrm{~mm}$, and $1 \sim 5 \mathrm{~mm}$. The average of the acoustic experiment results from the three replicates is calculated and shown in Figures 10 and 11. The results show that aggregate gradation influences the sound absorption coefficient. The aggregate gradation of $1 \sim 3 \mathrm{~mm}$ has the optimal acoustic absorption effect, followed by $1 \sim 5 \mathrm{~mm}$, while the effect of the aggregate gradation of $0 \sim 2 \mathrm{~mm}$ is the most undesirable. This result occurs because when the aggregate size is quite small, its internal pores and apertures are almost blocked and the air flow resistance becomes large. Additionally, with the decrease in aggregate size, the volume of the cement paste increases, while the volume of the pores 


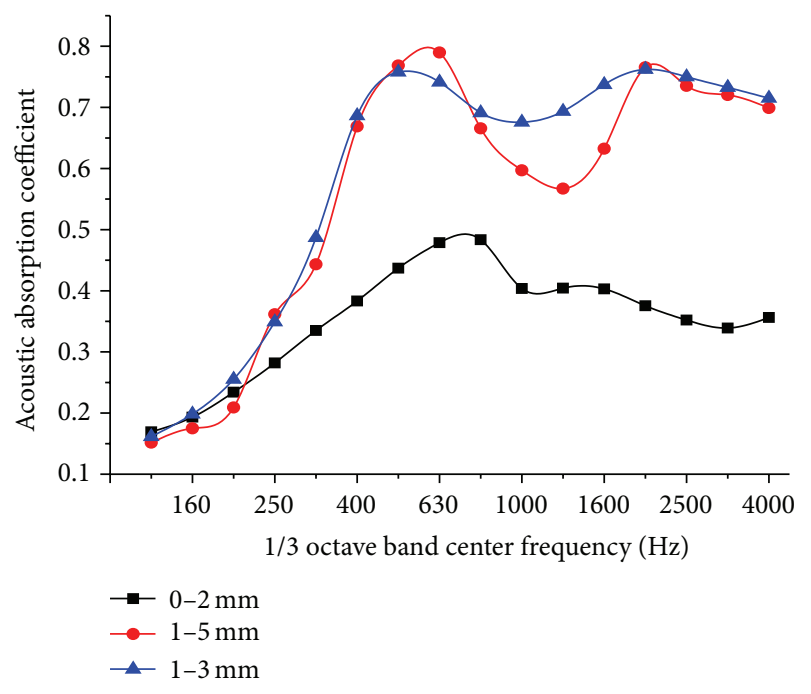

FIGURE 10: Relationship between aggregate size and sound absorption.

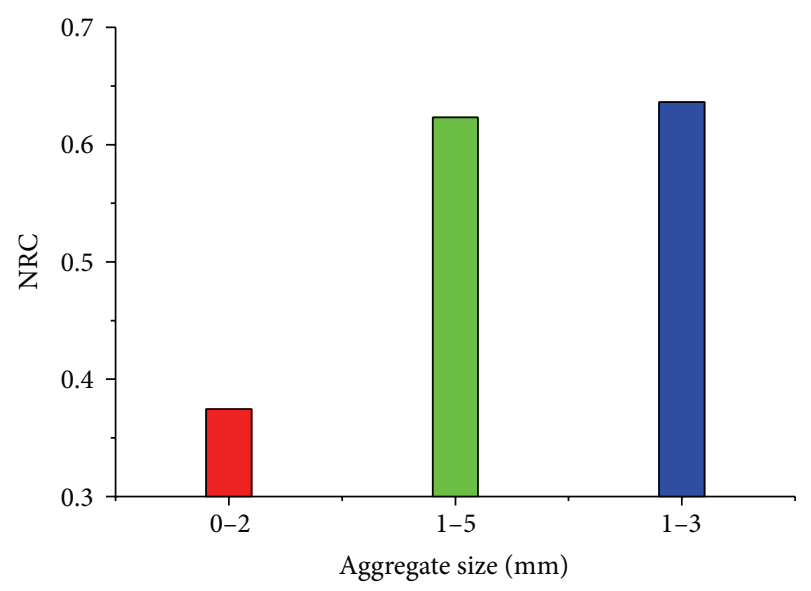

FIGURE 11: Variation of NRC with aggregate size.

created between the aggregates decreases. Thus, the sound wave cannot effectively travel into and through the porous materials, resulting in a considerably lower sound absorption coefficient. On the contrary, when the aggregate is large in size, the pores and apertures will be too large to give an acceptable acoustic absorption performance. Therefore, the optimal aggregate gradation is $1 \sim 3 \mathrm{~mm}$.

4.2. Relationship between Fibre and Sound Absorption. The effect of fibre was also investigated as a method of increasing the strength of porous concrete. The fourth group was studied with five gradations of fibre content, namely, $0.1 \%, 0.2 \%, 0.3 \%$, $0.4 \%$, and $0.5 \%$. Figure 12 shows the effect of fibre content on the acoustic absorption coefficient. From the two figures, it is clear that the acoustic absorption coefficient decreases with the increase in fibre content at low frequencies (below $500 \mathrm{~Hz}$ ) and increases with the increase in fibre content at high frequencies (above $500 \mathrm{~Hz}$ ). Figure 13 reveals the relationship between the noise reduction coefficient and the

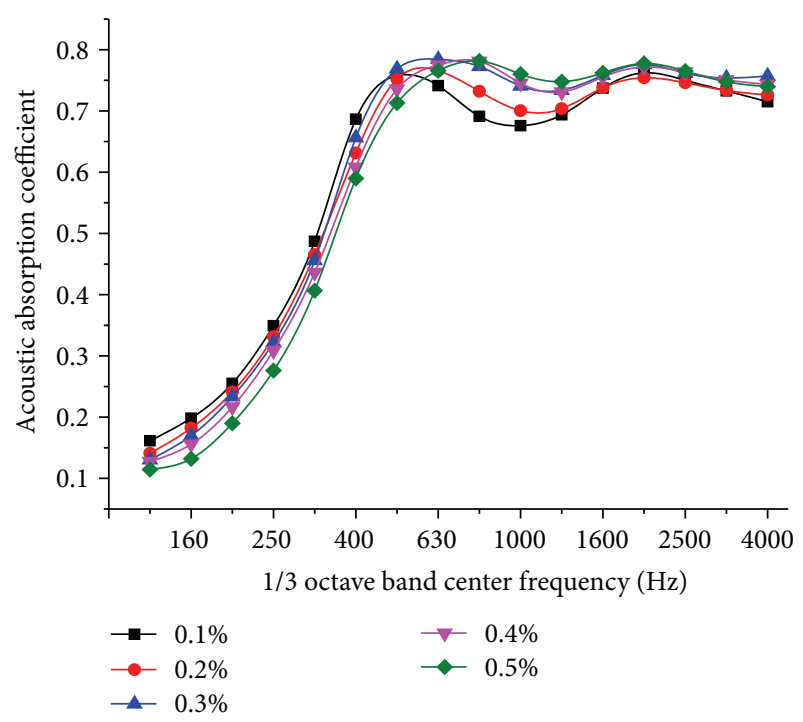

FIGURE 12: Relationship between fibre content and sound absorption.

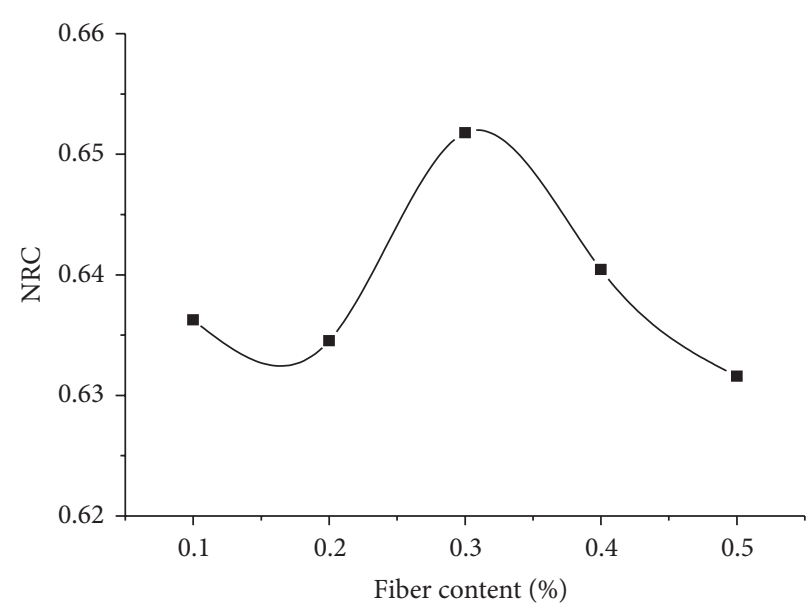

FIGURE 13: Variation of NRC with fibre content.

fibre content, indicating that the optimal fibre content for the noise reduction coefficient of porous concrete is $0.3 \%$ in this study.

Figure 14 represents the relationship between the fibre content and compressive strength of porous concrete. It shows that compressive strength first increases with the increase of fibre content and then decreases. This effect is associated with fibre dispersion. When the fibre content reaches a certain value, the fibre is difficult to mix; beyond that, fibre dispersion decreases, dramatically reducing compressive strength. When the fibre content is $0.3 \%$, the compressive strength reaches its maximum. Thus, the recommended amount of fibre filling is $0.3 \%$.

4.3. Relationship between Compaction Index and Sound Absorption. Compaction index, another important parameter that affects the strength and sound absorption property of porous concrete, was also discussed in this paper. A fifth group was 


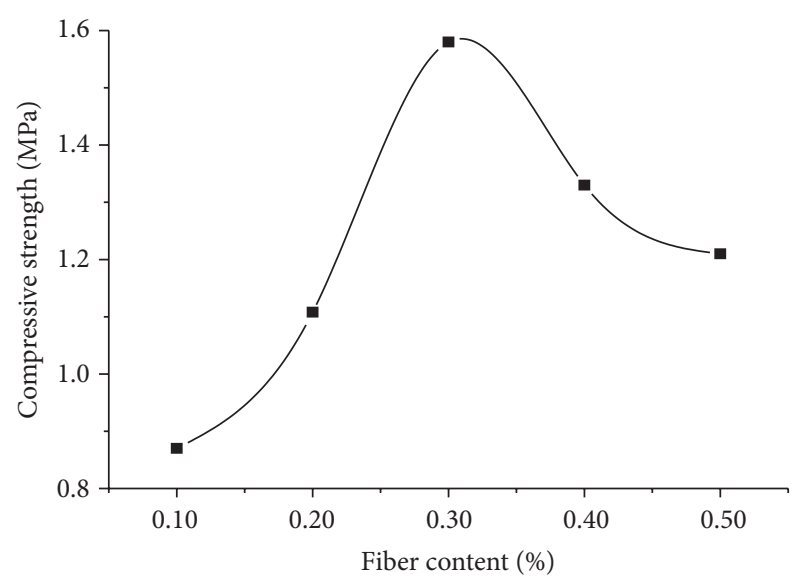

FigURE 14: Relationship between fibre content and compressive strength.

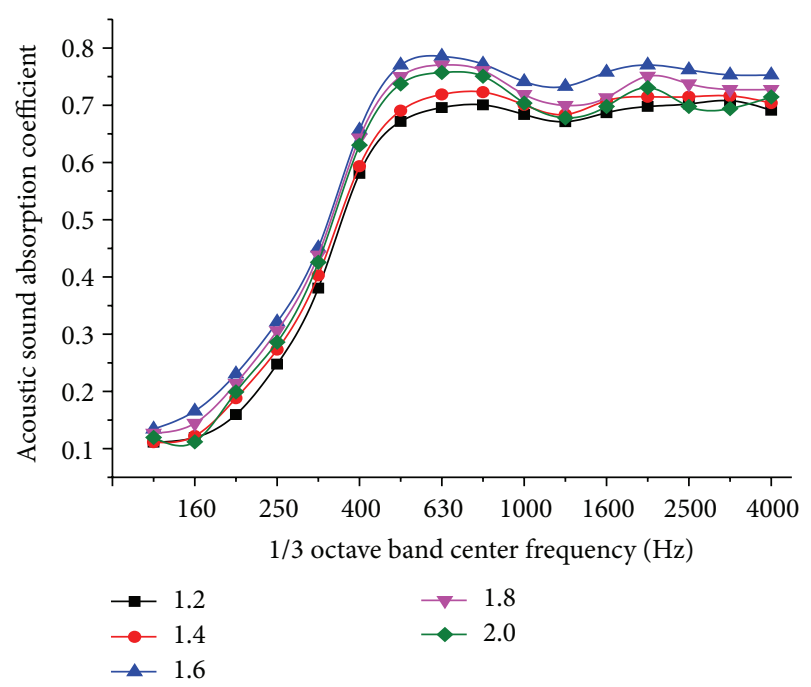

FIGURE 15: Relationship between compaction index and sound absorption.

studied with five different compaction indexes: 1.2, 1.4, 1.6, 1.8, and 2.0. The compaction index was calculated using the following equation:

$$
\text { Compaction index }=\frac{D_{2}}{D_{1}},
$$

where $D_{1}$ and $D_{2}$ are apparent densities of porous concrete formed by freely dropping into a mould according to the JCI method for making porous concrete specimens (draft). Figures 15 and 16 demonstrate the relationship between compaction index and sound absorption of porous concrete. It is clear that the acoustic absorption first increases and then decreases with increments of the compaction index and that the critical value is 1.6. This effect occurs because appropriate compression can produce micro cracks on pores and aperture walls, but a compaction index that is too large will block the pores and apertures of the porous concrete.

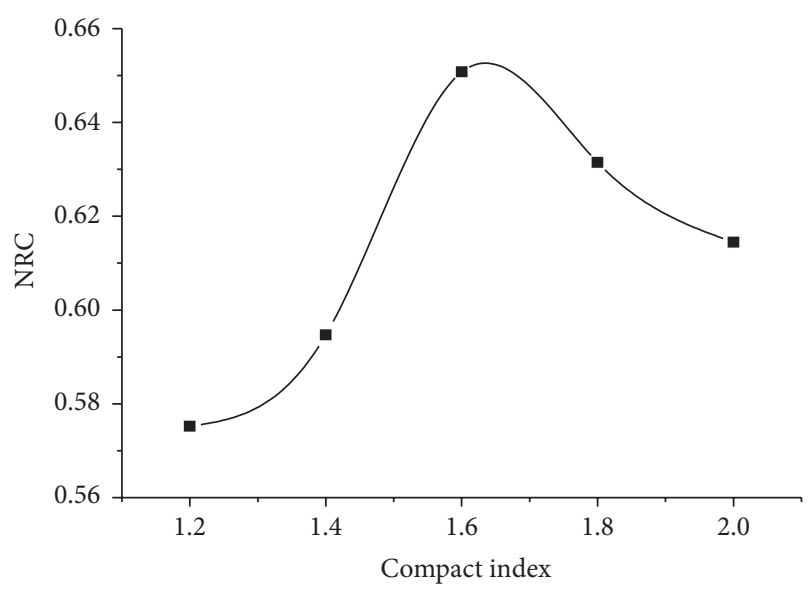

FIGURE 16: Variation of NRC with compaction index.

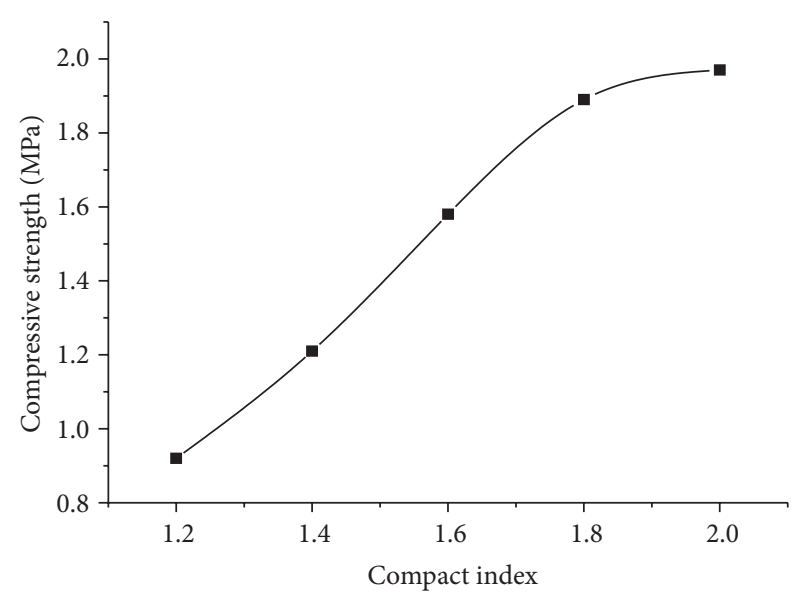

FIGURE 17: Relationship between compaction index and compressive strength.

Figure 17 presents the relationship between the compaction index and compressive strength of porous concrete. It is obvious that the compressive strength increases with the compaction index. Therefore, the optimal compaction index is 1.6 .

In summary, the laboratory experiments investigated the effect of aggregate type, aggregate combination, aggregate grain gradation, fibre and compaction index on acoustics, and strength characteristics. The test results showed that the optimum noise absorption could be obtained with the two-layer method, that is, with the combination of $8 \mathrm{~cm}$ slag (lower layer) and $12 \mathrm{~cm}$ expanded perlite (upper layer) forming a porous sound-absorbing concrete slab, and that the porous concrete material should have an aggregate grain gradation of $1-3 \mathrm{~mm}$, a fibre content of $0.3 \%$, and a compaction index of 1.6. These laboratory findings were then utilised to design a field test section for validation. 
TABLE 3: Mixture design of porous sound absorption concrete slab for the test.

\begin{tabular}{lccccccc}
\hline $\begin{array}{l}\text { Expanded } \\
\text { perlite }\end{array}$ & Slag & Cement & $\begin{array}{c}\text { Water/cement } \\
\text { ratio }\end{array}$ & $\begin{array}{c}\text { Polyester } \\
\text { fibre }\end{array}$ & $\begin{array}{c}\text { Water reducing } \\
\text { agent }\end{array}$ & $\begin{array}{c}\text { Foaming } \\
\text { agent }\end{array}$ & $\begin{array}{c}\text { Foam-stabilising } \\
\text { agent }\end{array}$ \\
\hline $35 \%$ & $25 \%$ & $30 \%$ & 0.2 & $0.3 \%$ & $0.75 \%$ & $1.95 \%$ & $1 \%$ \\
\hline
\end{tabular}

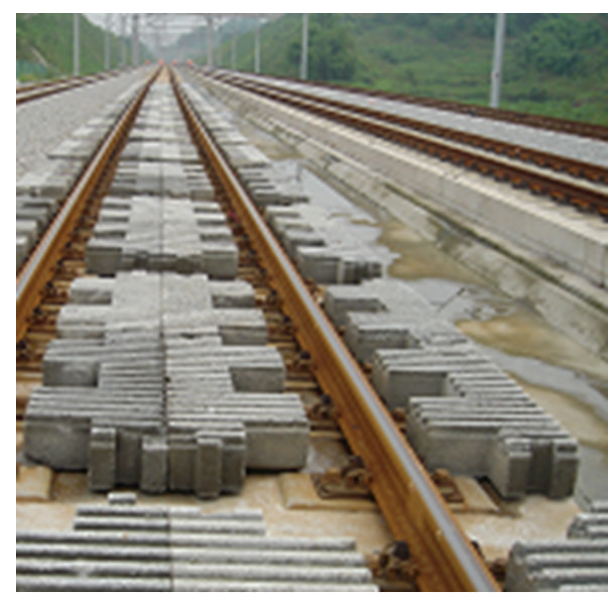

FIGURE 18: Photo of the test section.

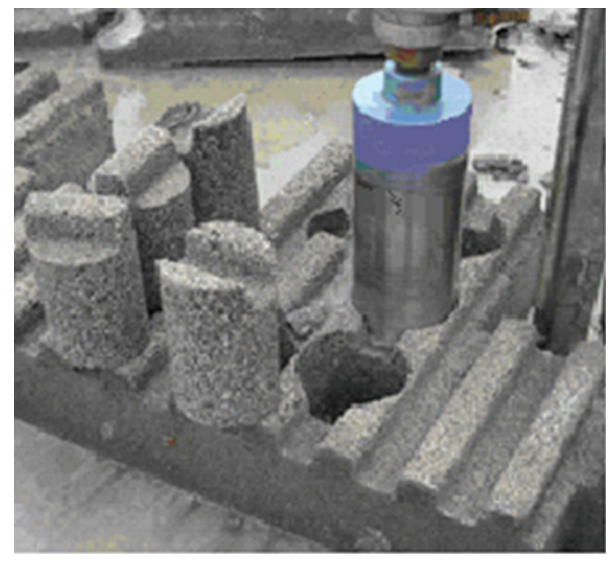

FIGURE 19: Field core from a porous sound-absorbing concrete slab.

\section{In Situ Noise Measurements}

To verify the findings from the laboratory research, a test section with porous sound-absorbing concrete slabs was set up at the Suining-Chongqing Railway Line in China, as illustrated in Figure 18. To improve the sound absorption performance of the slab, $40 \mathrm{~mm} \times 40 \mathrm{~mm}$ grooves perpendicular to the railway line were cut into the slab surface, as shown in Figure 19. The contents of cement, aggregate, water, fibre, and admixtures in the mixture are shown in Table 3.

5.1. Sound Absorption Coefficient of the Sound-Absorbing Slab. After construction, cylinder specimens were cored from the test cells to test the sound-absorbing property. A typical core is shown in Figure 19. Five samples were cored and tested for the acoustic absorption coefficient with the abovementioned standing wave tube method. Test results showed that the

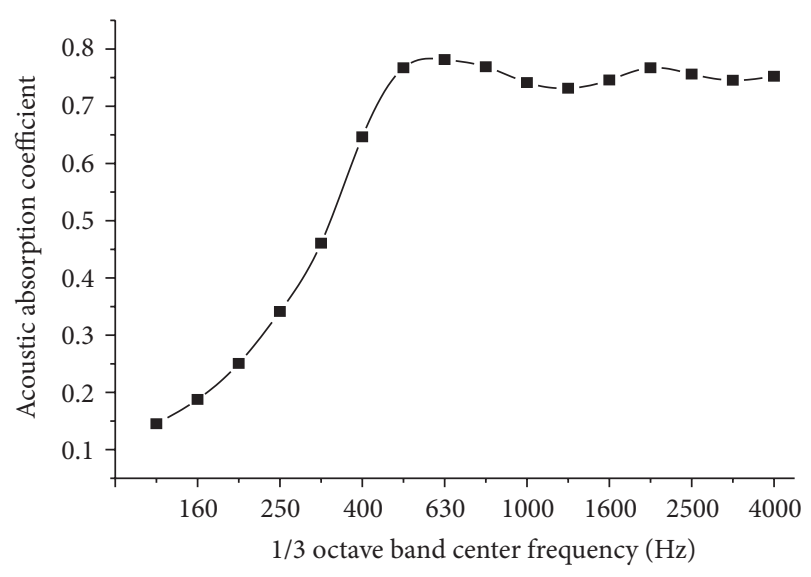

FIGURE 20: Average sound-absorbing property of the specimens.

samples had similar sound-absorbing properties. The average of the acoustic experiment results from the five samples is shown in Figure 20.

5.2. Noise Measurement from the Test Section. Field measurements at two test sites were conducted with the arrangement shown in Figure 21. Each site has two test points. The distance between the two sites is $200 \mathrm{~m}$, and one site is in the middle of the $200 \mathrm{~m}$ long sound observation test section. The test points at each site are $7.5 \mathrm{~m}$ and $30 \mathrm{~m}$ away from the railway centre line. The data for the sound pressure response were recorded at time increments of $0.0002 \mathrm{~s}$ with the use of the CS-3008 system produced by Germany IMC, Ltd., ENDEVCO-8515C pressure sensors, a wireless remote monitoring system, GPS, and a wireless remote data transmission system. It should be noted that the positions of measuring points number 1 and number 3 in this arrangement were slightly different from what is described in the Chinese National Standards (GB 12525-90); the main reason for this modification was to investigate the effect of the porous sound-absorbing concrete slabs in close proximity to the railway.

The CRH2-300 vehicle was used throughout the entire experiment at speeds of $80,100,120,140,160,180$, and $200 \mathrm{~km} / \mathrm{h}$ to ensure the stability and continuity of the test. The sound-absorbing effect of the concrete slabs at the speed of $140 \mathrm{~km} / \mathrm{h}$ shown in Figure 22 indicates that the noise level obtained from observation point number 1 is lower than that from number 3, unless the frequency is $0 \sim 100 \mathrm{~Hz}$. That is to say, the porous sound-absorbing concrete slab has a good noise reduction effect in the middle and high frequency range of $100 \sim 4000 \mathrm{~Hz}$. The overall noise level from number 1 is, in general, $3.46 \mathrm{~dB}$ lower than that from number 3; therefore the noise reduction of the sound-absorbing slab is approximately $3.46 \mathrm{~dB}$ in close proximity to the railway. Furthermore, it also 


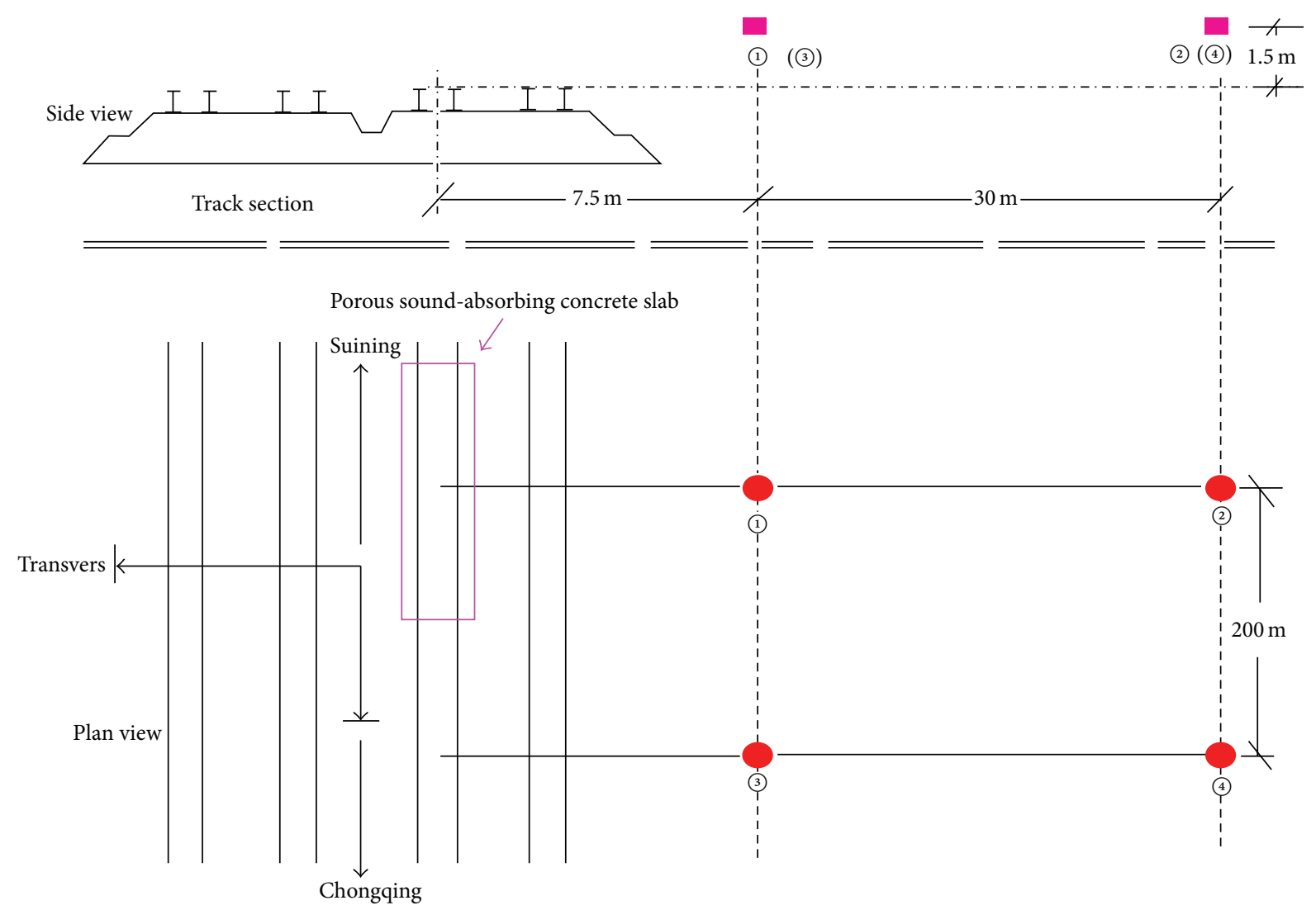

FigURE 21: In situ measurement arrangement.

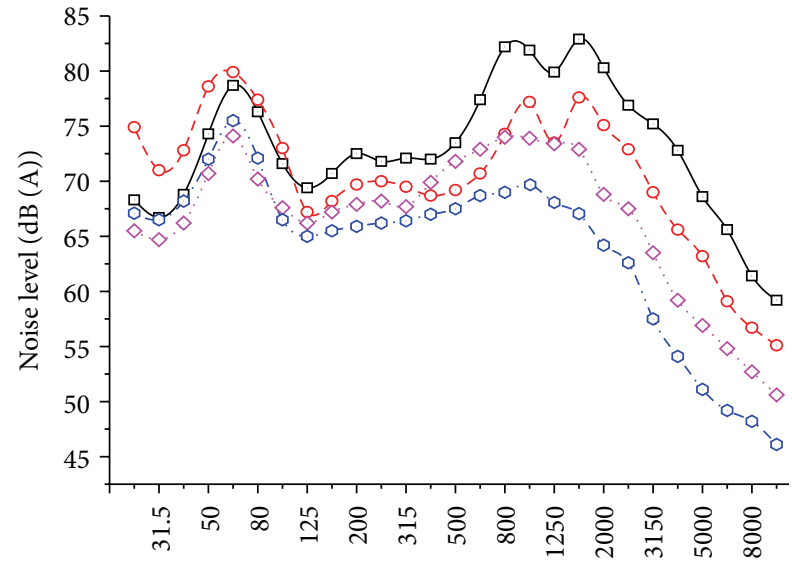

$1 / 3$ octave band center frequency $(\mathrm{Hz})$

$\begin{array}{lll}\rightarrow-\text { Observation point number } 3 & \cdots \diamond \cdots & \text { Observation point number } 4 \\ -\diamond-\text { Observation point number } 1 & . \diamond . . & \text { Observation point number } 2\end{array}$

FIGURE 22: Sound-absorbing effect of the sound absorption slab.

can be seen that the noise level obtained from observation point number 2 is lower than that from number 4 , unless the frequency is $0 \sim 80 \mathrm{~Hz}$, which means that the sound-absorbing slab has a good noise reduction effect in the middle and high frequency range of $80 \sim 4000 \mathrm{~Hz}$. The overall noise level from number 2 is, in general, $2.7 \mathrm{~dB}$ lower than that from number 4 .

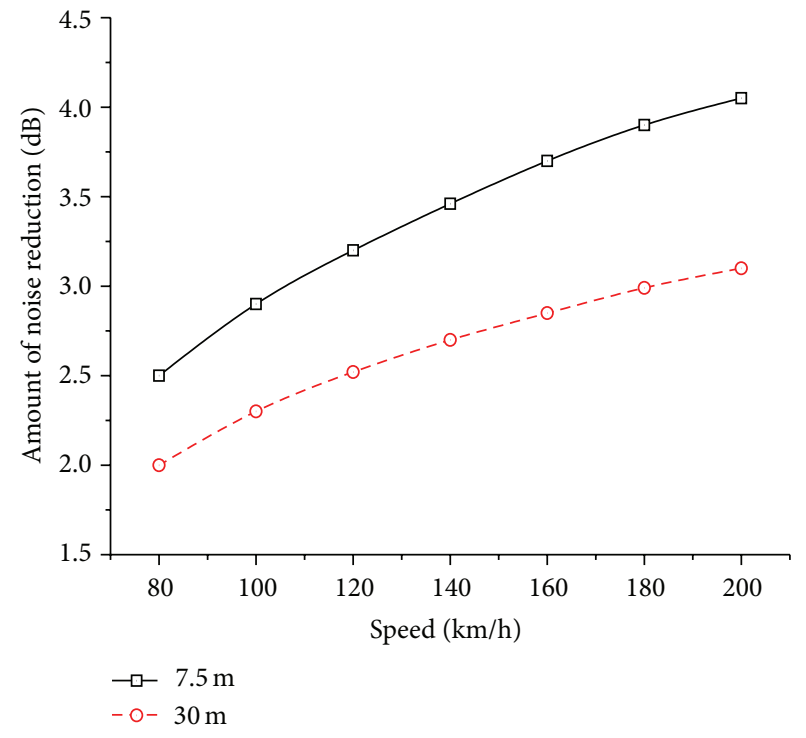

FIGURE 23: Amount of noise reduction at different speeds.

The effect of vehicle speed on the noise reduction of the porous sound-absorbing concrete slab was also investigated, and the results are plotted in Figure 23. The results show that the porous sound-absorbing concrete slab can significantly reduce the railway noise at different vehicle speeds; the amount of noise reduction changes roughly linearly with 
vehicle speed. The least amount of noise reduction is approximately $2.5 \mathrm{~dB}$ at the speed of $80 \mathrm{~km} / \mathrm{h}$, and the maximum is $4.05 \mathrm{~dB}$ at the speed of $200 \mathrm{~km} / \mathrm{h}$.

\section{Conclusions and Discussion}

To reduce the noise from the lower part of the train, a porous sound-absorbing concrete slab was developed, and its sound absorption was examined in this study. First, the acoustical absorption coefficients of porous concrete materials were measured in the laboratory, to study the effect of various aggregate types, combinations of different aggregates, and aggregate gradations. Furthermore, the influence of the fibre content and compaction index on sound absorption was examined. Then, the findings from the laboratory study were applied to make porous sound-absorbing concrete slabs that were arranged in a test section. The railway noise in the test section was measured according to Chinese National Standards (GB 12525-90) at different vehicle speeds. The following conclusions can be drawn from the discussion above.

(a) The porous concrete with expanded perlite aggregate has the best sound absorption property, followed by the slag; clay ceramsite exhibits the worst sound absorption property. For the two-layer method, the combination of $8 \mathrm{~cm}$ slag (lower layer) and $12 \mathrm{~cm}$ expanded perlite (upper layer) is better than the other combinations; for the $8+12 \mathrm{~cm}$ combination, the maximum NRC is 0.623 and the density of the specimen is approximately $820 \mathrm{~kg} / \mathrm{m}^{3}$. The aggregate gradation had a significant effect on acoustic absorption properties of porous concrete, with an optimal aggregate gradation of $1 \sim 3 \mathrm{~mm}$.

(b) Fibre has an effect on not only the strength of porous concrete but also its acoustic absorption property. The optimum fibre content is $0.3 \%$.

(c) Similarly, the effect of the compaction index was studied. Compressive strength increases with the compaction index. Therefore, the best compaction index is 1.6.

(d) Porous sound-absorbing concrete slabs can significantly reduce railway noise at different vehicle speeds, and the amount of the noise reduction changes roughly linearly with the vehicle speed when the train is traveling at less than $200 \mathrm{~km} / \mathrm{h}$. The maximum reduction measured was $4.05 \mathrm{~dB}$ at the speed of $200 \mathrm{~km} / \mathrm{h}$

\section{Conflict of Interests}

The authors declare that there is no conflict of interests regarding the publication of this paper.

\section{Acknowledgment}

This research is sponsored by the National Natural Science Foundation of China, no. U1234201. This support is gratefully acknowledged. The results and opinions presented are those of the authors and do not necessarily reflect those of the sponsoring agencies.

\section{References}

[1] M. J. M. M. Steenbergen, A. V. Metrikine, and C. Esveld, "Assessment of design parameters of a slab track railway system from a dynamic viewpoint," Journal of Sound and Vibration, vol. 306, no. 1-2, pp. 361-371, 2007.

[2] R. J. Diehl, R. Nowack, and G. Hölzl, "Solutions for acoustical problems with ballastless track," Journal of Sound and Vibration, vol. 231, no. 3, pp. 899-906, 2000.

[3] J. Ma, "Evaluation and analysis on the effect of noise mitigation measures for railway with ballastless track," Railway Occupational Safety, Health \& Environmental Protection, vol. 35, no. 3, pp. 111-115, 2008 (Chinese).

[4] B. Tian, Y. Liu, K. Niu, S. Li, J. Xie, and X. Li, "Reduction of tire-pavement noise by porous concrete pavement," Journal of Materials in Civil Engineering, vol. 26, no. 2, pp. 233-239, 2014.

[5] T. Kurita, Y. Wakabayashi, H. Yamada et al., "Reduction of wayside noise from Shinkansen high-speed trains," Journal of Mechanical Systems for Transportation and Logistics, vol. 4, no. 1, pp. 1-12, 2011.

[6] K. Yoshiki, K. Takeshi, Y. Harlow et al., "Reduction of noise generated from the lower part of the Shinkansen car with sound-absorbing slabs," in Proceedings of the 9th World Congress on Railway Research, Lille, France, 2011.

[7] H. K. Kim and H. K. Lee, "Acoustic absorption modeling of porous concrete considering the gradation and shape of aggregates and void ratio," Journal of Sound and Vibration, vol. 329, no. 7, pp. 866-879, 2010.

[8] H. K. Kim and H. K. Lee, "Influence of cement flow and aggregate type on the mechanical and acoustic characteristics of porous concrete," Applied Acoustics, vol. 71, no. 7, pp. 607-615, 2010.

[9] K. Bruce, Ferguson. Porous Pavements, CRC Press, Boca Raton, Fla, USA, 2005.

[10] V. Tiwari, A. Shukla, and A. Bose, "Acoustic properties of cenosphere reinforced cement and asphalt concrete," Applied Acoustics, vol. 65, no. 3, pp. 263-275, 2004.

[11] S. B. Park, D. S. Seo, and J. Lee, "Studies on the sound absorption characteristics of porous concrete based on the content of recycled aggregate and target void ratio," Cement and Concrete Research, vol. 35, no. 9, pp. 1846-1854, 2005.

[12] C. Cianfrini, M. Corcione, and L. Fontana, "Experimental verification of the acoustic performance of diffusive roadside noise barriers," Applied Acoustics, vol. 68, no. 11-12, pp. 1357$1372,2007$.

[13] N. Neithalath, A. Marolf, J. Weiss, and J. Olek, "Modeling the influence of pore structure on the acoustic absorption of enhanced porosity concrete," Journal of Advanced Concrete Technology, vol. 3, no. 1, pp. 29-40, 2005. 

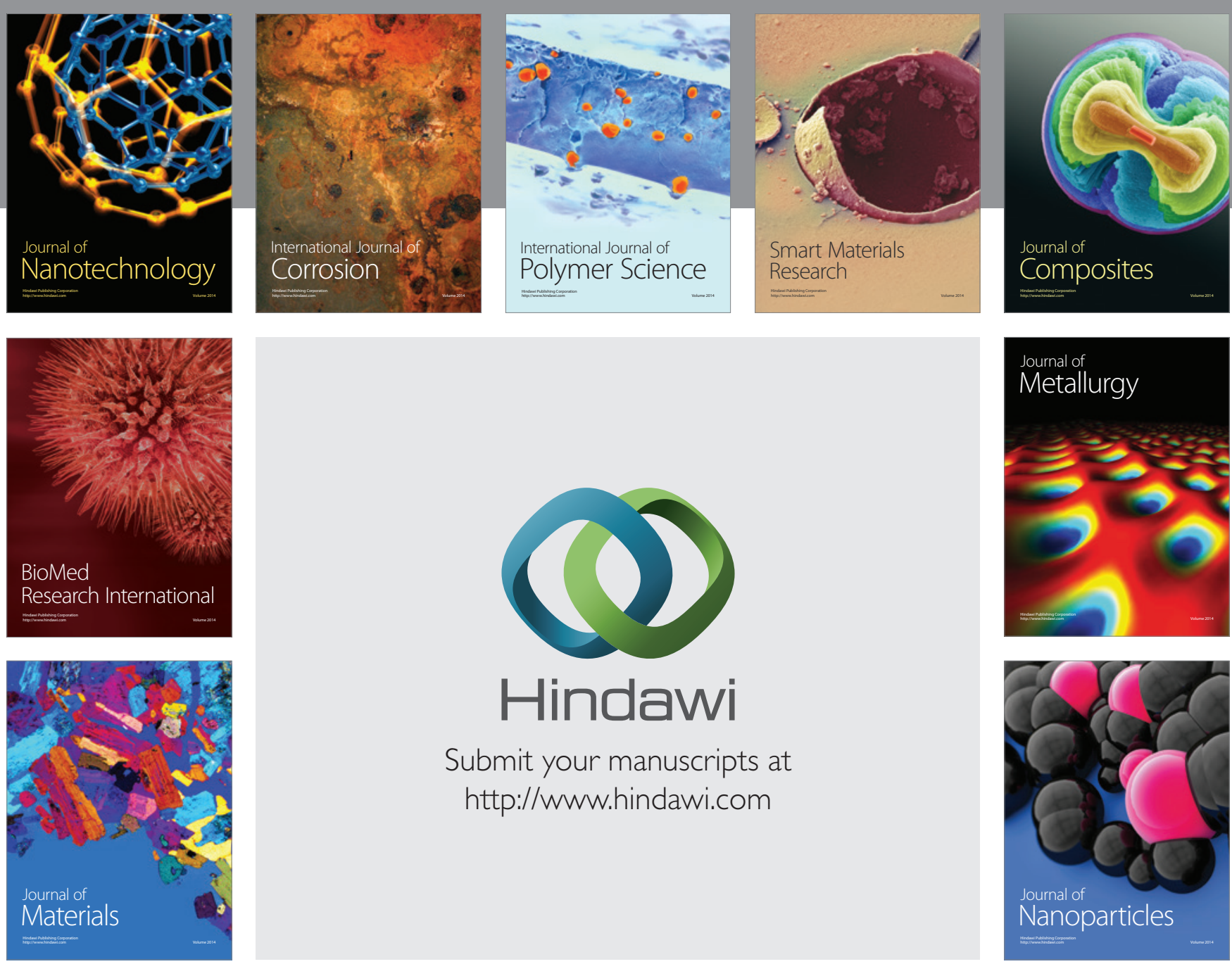

Submit your manuscripts at http://www.hindawi.com
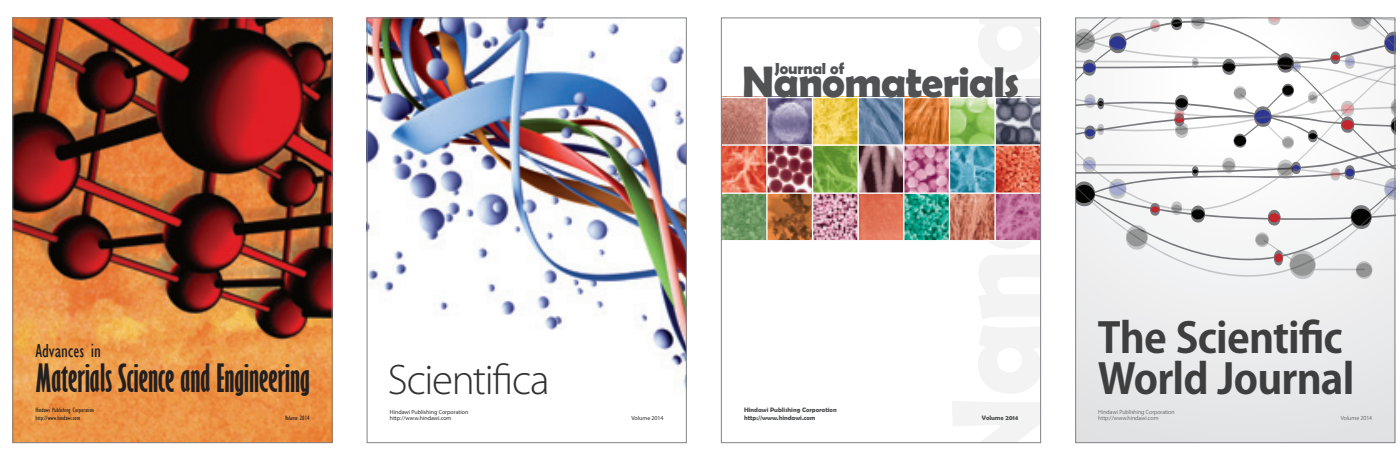

\section{The Scientific World Journal}
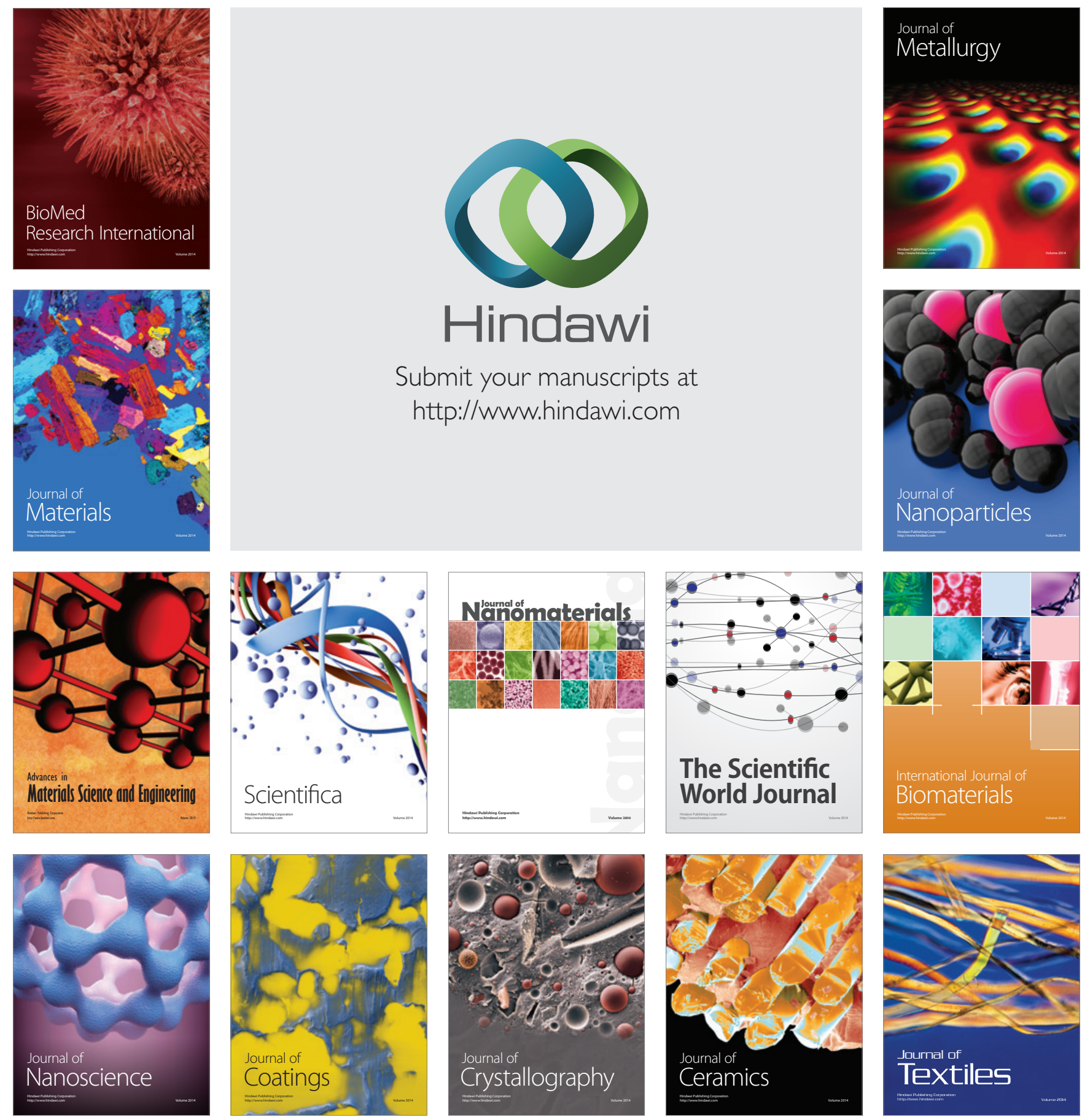